\title{
PENGARUH KUALITAS PELAYANAN DAN PERCEIVED VALUE TERHADAP LOYALITAS PASIEN: KEPUASAN PASIEN SEBAGAI MEDIASI
}

\author{
Ivy Vania Ariany \\ Program Studi Magister Manajemen Universitas Tarumanagara \\ ivyvania96@gmail.com \\ Anas Lutfi \\ Program Studi Magister Manajemen Universitas Tarumanagara \\ Masuk : 15-11-2020, revisi : 19-12-2020 diterima untuk diterbitkan : 21-12-2020
}

\begin{abstract}
The purpose of this paper is to explore the relationship of service quality and perceived value on patients' satisfaction and loyalty which are vital for successful dental clinic management. A survey was conducted on 100 patients at a dental clinic in Brebes, Indonesia in September $9^{\text {th }}-16^{\text {th }}, 2020$. The data was collected using non-probability sampling and analized using Statistical Package for the Social Sciences (SPSS) software. The results of SPSS showed that service quality and perceived value had a positive and significant impact on patients' satisfaction and loyalty, satisfaction had a positive and significant impact on patients' loyalty, and further, patients' satisfaction significantly mediates the relationship of service quality and perceived value on patients' loyalty. Findings of the current study can contribute to give a broader perception of behavioural mechanisms management in both clinic and hospital world. Healthcare workers should pay more attention on creating positive patients' perceived value to increase their loyalty.
\end{abstract}

Keywords: Service Quality, Perceived Value, Satisfaction, Loyalty, Dental Clinic

Abstrak: Tujuan penelitian ini adalah melihat pengaruh kualitas pelayanan dan perceived value terhadap kepuasan dan loyalitas pasien. Penelitian ini menggunakan survei yang dibagikan pada 100 pasien pada sebuah klinik gigi di Brebes dari tanggal 9 September hingga 16 September 2020. Pengambilan sampel menggunakan metode non-probability sampling dan dianalisa menggunakan software SPSS. Hasil SPSS menunjukkan bahwa kualitas pelayanan dan perceived value memiliki pengaruh positif dan signifikan terhadap kepuasan dan loyalitas pasien, kepuasan memiliki pengaruh positif dan signifikan terhadap loyalitas pasien, serta kepuasan pasien memediasi pengaruh kualitas pelayanan dan perceived value terhadap loyalitas pasien. Hasil penelitian ini dapat memberikan persepsi yang lebih luas mengenai manajemen klinik dan rumah sakit. Para tenaga kesehatan harus lebih berusaha menciptakan persepsi positif kepada pasien agar pasien tetap loyal.

Kata Kunci: Kualitas Pelayanan, Nilai Persepsi, Kepuasan, Loyalitas, Klinik Gigi

\section{PENDAHULUAN}

\section{Latar Belakang}

Meningkatnya kesadaran masyarakat Indonesia akan pentingnya kesehatan serta program Badan Penyelenggara Jaminan Sosial (BPJS) Kesehatan yang diselenggarakan oleh pemerintah menyebabkan usaha waralaba kesehatan semakin menjanjikan, terutama dibidang apotek, klinik kesehatan, dan klinik gigi (detik finance, 2014). Ketua Umum Pengurus Besar Persatuan Dokter Gigi Indonesia, Drg. Farichah Hanum, Mkes juga mengemukakan bahwa pertumbuhan industri kedokteran gigi mengalami pertumbuhan $20 \%$ setiap tahunnya yang membuat Indonesia muncul sebagai "pasar" peluang perkembangan industri kedokteran gigi (Putra \& Fizriyani, 2017). 
Berbagai perubahan dalam industri pelayanan kesehatan telah memberikan tekanan besar pada penyedia layanan kesehatan untuk terus bertahan dan berkembang (Wei-Jiao, 2017). Berbagai sektor seperti perbankan, pariwisata, transportasi, dan layanan kesehatan semuanya membutuhkan pelanggan yang loyal agar dapat bertahan pada lingkungan bisnis yang semakin menantang. Mengingat meningkatnya jumlah rumah sakit dan klinik di Indonesia menunjukkan bahwa terdapat peningkatan ekonomi di Indonesia dengan pasien sebagai pelanggan (Julianto, 2016), maka rumah sakit dan klinik perlu mempertahankan pasien yang loyal agar dapat terus bertahan hidup (Tosyali et al, 2019).

Mengembangkan dan mempertahankan loyalitas pasien akan membawa manfaat bagi pasien dengan meningkatkan kesehatan mereka. (Rundle \& Russell, 2010). Pasien yang loyal juga akan tetap menggunakan layanan medis, mengikuti seluruh rencana perawatan dan menjaga hubungan dengan penyedia layanan kesehatan (MacStravic, 1994). Semakin baik kualitas pelayanan yang diberikan, maka semakin tinggi tingkat kepuasan dan loyalitas kustomer (Kaura et al., 2015). Caruana dan Fenech (2005) mengungkapkan bahwa untuk meningkatkan kepuasan pasien, seorang dokter harus dapat meningkatkan persepsi nilai (perceived value). Perceived value dapat mempengaruhi loyalitas pelanggan (Dolarsland, 2014). Penelitian-penelitian sebelumnya juga menyebutkan bahwa kepuasan pelanggan terhadap produk atau jasa akan berdampak positif terhadap loyalitas (Moliner 2009; Hur et al., 2009; Kim \& Park, 2016).

Berdasarkan uraian diatas, maka tujuan penelitian ini adalah untuk mengetahui pengaruh kualitas pelayanan dan perceived value terhadap loyalitas pasien dengan kepuasan pasien sebagai mediasi.

\section{TELAAH KEPUSTAKAAN Kualitas Pelayanan}

Kualitas pelayanan didefinisikan oleh Lewis (1991) "service quality is a measure of how well the service delivered meets the expectations of service." Menurut Kotler (1997) kualitas pelayanan merupakan "an action or an activity which can be offered by a party to another party, which is basically intangible and can not affect any ownership. Service may be related to tangible product or intangible product". Berdasarkan uraian diatas, maka penulis mendefinisikan kualitas pelayanan merupakan sebuah tindakan atau kegiatan yang ditawarkan oleh satu pihak ke pihak lain. Service ini dapat berhubungan dengan produk yang berwujud dan yang tidak berwujud.

\section{Perceived Value}

Menurut Zaithaml (1988), perceived value adalah "the consumer's overall assessment of the utility of a product based on the perceptions of what is received and what is given." Ravald \& Gronroos (1996) menyatakan bahwa "perceived value is a comparison between what a purchase has contributed of 'getting' and what it has involved of 'giving'. Hal-hal yang diberikan merupakan harga, waktu, usaha, maupun resiko. Sedangkan manfat-manfat yang diterima dapat dalam bentuk ekonomi maupun sosial (Oh, 2003; Cronin,2000). Berdasarkan uraian diatas, maka penulis mendefinisikan perceived value sebagai persepsi penilaian keseluruhan terhadap utilitas suatu produk atau jasa berdasarkan apa yang diterima dan apa yang diberikan.

\section{Kepuasan}

Oliver (1981) mendefinisikan kepuasan sebagai "Satisfaction is a summary of psychological state resulting when the emotion surrounding disconfirmed expectations is coupled with the consumer's prior feelings about the consumption experience". Tse et al. (1988) mendefinisikan kepuasan sebagai "the consumer's response to the evaluation of discrepancy between prior expectations and the actual performance of the product as perceived after its consumption". Kotler (2000) mendefinisikan kepuasan sebagai "satisfaction is a person's feelings of pleasure or disappointment resulting from comparing a product's 
perceived performance (or outcome) in relation to his or her expectations." Berdasarkan uraian diatas, maka penulis mendefinisikan kepuasan sebagai keadaan psikologis emosi konsumen secara keseluruhan terhadap perbedaan antara harapan-harapan sebelumnya dengan hasil yang sesungguhnya terhadap produk atau jasa yang telah dirasakan.

\section{Loyalitas}

Oliver (1999) mendefinisikan loyalitas sebagai "A deeply held commitment to re-buy or re-patronize a preferred product or service in the future despite situational influences and marketing efforts having the potential to cause switching behavior." Zineldin (2006) mendefinisikan loyalitas sebagai "a customer's engagement with a company and willingness to continue doing business with a company permanently." Berdasarkan uraian diatas, maka penulis mendefinisikan loyalias sebagai sebuah komitmen kustomer terhadap produk atau jasa yang disukai dan keinginan untuk melanjutkan bisnis dengan perusahaan meskipun terdapat perubahan situasi.

\section{Kerangka Penelitian}

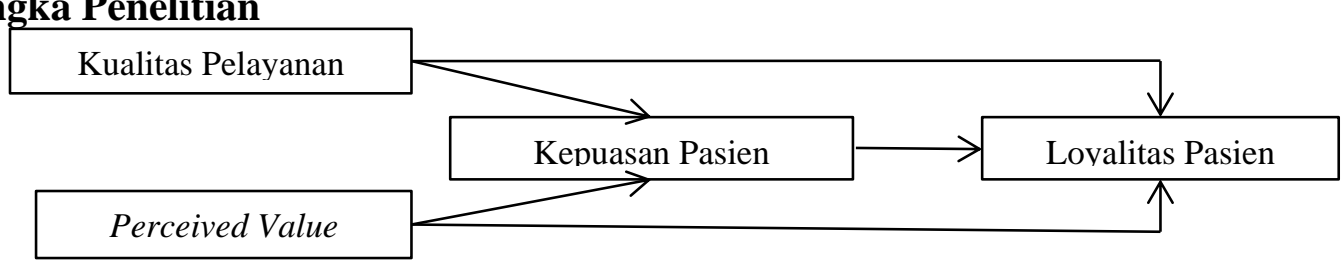

\section{Gambar 1}

\section{Model Penelitian}

\section{METODE PENELITIAN}

Penelitian ini merupakan penelitian deskriptif dengan rancangan penelitian crosssectional. Teknik penarikan sampel menggunakan teknik purposive sampling. Penelitian ini dilakukan dari 9 September 2020 sampai 16 September 2020. Sampel penelitian ini adalah pasien yang minimal berusia 18 tahun, telah menjalani perawatan gigi dalam 1 tahun terakhir, dan bersedia untuk mengikuti penelitian ini. Total kuesioner yang berhasil dikumpulan sebanyak 122 kuesioner, namun hanya 100 kuesioner yang dapat digunakan. Sebanyak 22 responden tidak memenuhi kriteria inklusi. Indikator-indikator variabel penelitian ini menggunakan skala Likert dengan skala 1-5 dengan nilai 1 (sangat tidak setuju) hingga nilai 5 (sangat setuju).

Pada 38 butir pernyataan telah dilakukan pengujian alat ukur dan didapatkan 34 butir pernyataan yang dinyatakan valid karena nilai Corrected Item-Total Correlation > 0,3 (Kumar, 2015) dan reliabel karena nilai Cronbach's Alpha > 0,7 (Sekaran \& Bougie, 2016). Maka, semua indikator pernyataan telah memenuhi persyaratan sebagai alat ukur.

\section{HASIL DAN PEMBAHASAN}

Tabel 1

Hasil Analisis Regresi

\begin{tabular}{lll}
\hline Hipotesis & Variabel & Persamaan Regresi \\
\hline $\mathbf{H}_{1 \mathbf{a}}$ dan $\mathbf{H}_{\mathbf{1}}$ & Kualitas pelayanan dan perceived value $\rightarrow$ kepuasan & $\mathrm{KE}=1.624+0.083 \mathrm{KP}+0.390 \mathrm{PV}$ \\
\hline $\mathbf{H}_{2 \mathrm{a}}$ dan $\mathbf{H}_{2 \mathbf{b}}$ & Kualitas pelayanan dan perceived value $\rightarrow$ loyalitas & $\mathrm{LP}=0.614+0.080 \mathrm{KP}+0.231 \mathrm{PV}$ \\
\hline $\mathbf{H}_{3}$ & Kepuasan $\rightarrow$ loyalitas pasien & $\mathrm{LP}=0.572+0.635 \mathrm{KE}$ \\
\hline
\end{tabular}

Pada tabel 1 didapatkan persamaan pertama, $\mathrm{LP}=0.614+0.080 \mathrm{KP}+0.231 \mathrm{PV}$, artinya kualitas pelayanan dan perceived value memiliki pengaruh positif masing-masing 0,080 dan 0,231 terhadap loyalitas pasien. Pada persamaan kedua, $\mathrm{KE}=1.624+0.083 \mathrm{KP}+0.390 \mathrm{PV}$, menunjukkan bahwa kualitas pelayanan dan perceived value memiliki pengaruh positif terhadap kepuasan pasien masing-masing 0,083 dan 0,390. Pada persamaan ketiga, LP $=0.572$ $+0.635 \mathrm{KE}$, menunjukan bahwa kepuasan memiliki pengaruh positif 0,635 terhadap loyalitas pasien. Pada tabel 1 ditemukan bahwa perceived value memiliki pengaruh positif yang lebih tinggi dibandingkan kualitas pelayanan. 
Tabel 2

Hasil Uji F (Anova)

\begin{tabular}{lll}
\hline Hipotesis & Variabel & Nilai Sig. \\
\hline $\mathbf{H}_{1 \mathbf{a}}$ dan $\mathbf{H}_{\mathbf{1 b}}$ & Kualitas pelayanan dan perceived value $\rightarrow$ kepuasan & 0.000 \\
\hline $\mathbf{H}_{2 \mathrm{a}}$ dan $\mathbf{H}_{2 \mathbf{b}}$ & Kualitas pelayanan dan perceived value $\rightarrow$ loyalitas & 0.000
\end{tabular}

Uji $\mathrm{F}$ digunakan untuk menguji signifikansi secara bersamaan variabel kualitas pelayanan dan perceived value terhadap kepuasan dan loyalitas pasien. Jika nilai $\alpha<0,05$, maka terdapat pengaruh yang signifikan (Raharjo, 2019). Oleh karena hasil pada tabel 2 menunjukan bahwa nilai signifikan $0,000<0,05$, maka kualitas pelayanan dan perceived value secara bersamaan berpengaruh signifikan terhadap kepuasan dan loyalitas pasien.

\section{Tabel 3}

Hasil Uji T

\begin{tabular}{lll}
\hline Hipotesis & Variabel & Nilai Sig. \\
\hline $\mathbf{H}_{\mathbf{1}}$ & Kualitas pelayanan $\rightarrow$ kepuasan & 0.038 \\
\hline $\mathbf{H}_{\mathbf{1 b}}$ & Perceived value $\rightarrow$ kepuasan & 0.000 \\
\hline $\mathbf{H}_{\mathbf{2}}$ & Kualitas pelayanan $\rightarrow$ loyalitas & 0.015 \\
\hline $\mathbf{H}_{\mathbf{2}}$ & Perceived value $\rightarrow$ loyalitas & 0.000 \\
\hline
\end{tabular}

Uji T digunakan untuk menguji sendiri-sendiri variabel kualitas pelayanan dan perceived value terhadap kepuasan dan loyalitas pasien. Jika nilai $\alpha<0,05$, maka terdapat pengaruh yang signifikan (Raharjo, 2019). Hasil pada tabel 2 menunjukan bahwa kualitas pelayanan dan perceived value secara sendiri-sendiri berpengaruh secara signifikan terhadap kepuasan dan loyalitas pasien oleh karena seluruh nilai signifikan $<0,05$.

\section{Tabel 4}

\section{Hasil Uji Sobel}

\begin{tabular}{lll}
\hline Hipotesis & Variabel & Nilai t \\
\hline $\mathbf{H}_{\mathbf{4}}$ & Kepuasan memediasi kualitas pelayanan $\rightarrow$ loyalitas & 6.044 \\
\hline $\mathbf{H}_{\mathbf{4}} \mathbf{b}$ & Kepuasan memediasi perceived value $\rightarrow$ loyalitas & 6.86 \\
\hline
\end{tabular}

Tabel 4 menunjukan bahwa nilai t hitung kualitas pelayanan terhadap loyalitas sebesar 6,044 > 1,96 dan nilai t hitung kualitas pelayanan terhadap loyalitas sebesar 6,044>1,96 maka kepuasan memediasi kualitas pelayanana dan perceived value terhadap loyalitas.

Hasil penelitian ini menunjukkan bahwa kualitas pelayanan memiliki pengaruh positif terhadap kepuasan pasien, maka $\mathrm{H}_{1 a}$ tidak ditolak. Hasil penelitian ini didukung oleh penelitian Lasadika (2019), Kaura et al. (2015), serta Keshavarz dan Jamshidi (2018). Berdasarkan hasil penelitian ini, maka dapat disimpulkan bahwa pelayanan yang tepat waktu dan sesuai jadwal dapat meningkatkan kepuasan pengunjung klinik. Pasien akan merasa semakin puas bila pelayanan selalu tersedia disaat pasien sedang membutuhkan. Selain itu, fasilitas-fasilitas klinik yang terlihat menarik secara visual dapat meningkatkan rasa puas pasien terhadap klinik.

Hasil penelitian ini menunjukkan bahwa perceived value atau nilai persepsi memiliki pengaruh positif terhadap kepuasan pasien, maka $\mathrm{H}_{1 b}$ tidak ditolak. Hasil penelitian ini didukung oleh penelitian Moliner (2009) serta Kim dan Park (2016). Berdasarkan hasil penelitian ini, dapat disimpulkan bahwa pasien akan semakin merasa puas jika klinik dapat menciptakan suasana yang menyenangkan, klinik dapat menciptakan gambaran-gambaran yang positif dibenak pasien, klinik dapat menawarkan tarif yang dianggap lebih baik dibandingkan klinik-klinik lainnya.

Hasil penelitian ini menunjukkan bahwa kualitas pelayanan memiliki pengaruh positif terhadap loyalitas pasien, maka $\mathrm{H}_{2 \mathrm{a}}$ tidak ditolak. Hasil penelitian ini didukung oleh penelitian Fatima et al. (2017) dan Meesala (2016). Berdasarkan hasil penelitian ini, maka dapat disimpulkan bahwa loyalitas pasien akan semakin meningkat apabila pelayanan klinik tepat waktu dan sesuai jadwal, pelayanan selalu tersedia disaat pasien sedang membutuhkan, dan fasilitas-fasilitas klinik yang terlihat menarik secara visual.

Hasil penelitian ini menunjukkan bahwa perceived value memiliki pengaruh positif terhadap loyalitas pasien, maka $\mathrm{H}_{2 b}$ tidak ditolak. Hasil penelitian ini didukung oleh penelitian Dölarslan (2012), Hur et al. (2012), serta Hardeep dan Neetu (2014). Berdasarkan hasil 
penelitian ini, maka dapat disimpulkan bahwa pasien akan terus berkunjung dan menggunakan layanan klinik bila pegawai memahami secara spesifik kebutuhan pasien pasien dan bila klinik memiliki jam operasional yang sesuai dengan keingan pasien. Pasien juga semakin loyal bila biaya perawatan yang dikeluarkan pasien sebanding dengan kualitas pelayanan yang diperoleh.

Hasil penelitian ini menunjukkan bahwa kepuasan memiliki pengaruh positif terhadap loyalitas pasien, maka $\mathrm{H}_{3}$ tidak ditolak. Hasil penelitian ini didukung oleh penelitian Moliner (2009), Rahmilia (2015), serta Keshavarz dan Jamshidi (2018). Berdasarkan hasil penelitian ini, maka dapat disimpulkan bahwa pasien akan semakin loyal jika pasien merasa puas, yaitu bila karyawan klinik berhasil menjadikan klinik sebagai tempat yang menyenangkan bagi pasien. Pasien semakin loyal bila pasien merasa puas dengan hasil perawatannya. Pasien menjadi semakin loyal bila perawatan memberikan hasil yang baik.

Hasil penelitian ini menunjukkan bahwa kepuasan memediasi pengaruh positif terhadap loyalitas pasien, maka $\mathrm{H}_{4 a}$ dan $\mathrm{H}_{4 b}$ tidak ditolak. Hasil penelitian ini didukung oleh penelitian Noermijati (2013), Kaura et al. (2015), serta Kim \& Park (2016). Berdasarkan hasil penelitian ini, dapat disimpulkan apabila karyawan klinik berhasil menciptakan kualitas pelayanan yang baik serta persepsi positif kepada pasien, hal itu akan memberikan dampak positif terhadap kepuasan pasien, yang pada akhirnya berdampak positif terhadap loyalitas pasien. Pasien yang loyal akan menggunakan klinik ini meskipun ada tawaran dari klinik lainnya. Pasien yang loyal akan cenderung menggunakan produk dan layanan tambahan klinik lainnya.

\section{KESIMPULAN DAN SARAN}

Hasil penelitian ini menunjukkan bahwa kualitas pelayanan dan perceived value memiliki pengaruh positif dan signifikan terhadap kepuasan dan loyalitas pasien. Kepuasan pasien memediasi hubungan kualitas pelayanan dan perceived value terhadap loyalitas pasien. Hasil penelitian ini juga menunjukkan bahwa perceived value berpengaruh lebih besar dibandingkan kualitas pelayanan.

Implikasi manajerial dari penelitian ini untuk klinik secara umum adalah agar klinik terus mempertahankan kualitas pelayanan dan perceived value yang baik. Salah satu indikator kualitas pelayanan adalah pelayanan yang tepat waktu dan sesuai jadwal. Pasien merasa puas dengan pelayanan klinik bila pasien tidak perlu berlama-lama menunggu antrian untuk mendapatkan perawatan dokter. Selain itu, kualitas pelayanan yang baik adalah bila pasien mendapati pelayanan klinik yang selalu tersedia saat pasien sedang membutuhkan. Kemudian, kualitas pelayanan dianggap baik bila fasilitas-fasilitas klinik yang terlihat menarik secara visual. Klinik dapat secara rutin melakukan perbaikan perabotan, cat tembok, dan berpenampilan rapih dan bersih. Klinik dapat meningkatkan perceived value pasien dengan cara menciptakan suasana yang menyenangkan di klinik. Hal itu dapat dilakukan dengan cara pemberian pelayanan yang ramah serta menambahkan fasilitas seperti pendingin ruangan dan wifi. Terakhir, klinik sebaiknya menetapkan tarif perawatan gigi yang baik dibandingkan klinik-klinik lainnya untuk meningkatkan persepsi pasien terhadap klinik. Klinik dapat melakukan survey mengenai tarif pada setiap kustomer yang datang agar klinik bisa menentukan harga yang tepat.

\section{DAFTAR PUSTAKA}

Caruana, A., \& Fenech, N. (2005). The effect of perceived value and overall satisfaction on loyalty: A study among dental patients. Journal of Medical Marketing, 5, 245-255.

Chahal, H., \& Kumari, N. (2011). Consumer perceived value and consumer loyalty in the healthcare sector. Journal of Relationship Marketing, 10(2), 88-112

Detik finance. (2014). Retrieved from October 12, 2019, from https://finance.detik.com/berita-ekonomi-bisnis/d-2532029/ini-bisnis-waralaba-palingmoncer-tahun-ini 
Dölarslan, E. S. (2014). Assessing the effects of satisfaction and value on customer loyalty behaviors in service environments: High-speed railway in Turkey as a case study. Management research review, 37, 706-727.

Fatima, T., Malik, S., \& Shabbir, A. (2018). Hospital healthcare service quality, patient satisfaction and loyalty: An investigation in context of private healthcare systems. International Journal of Quality \& Reliability Management, 35.

Hur, W. M., Kim, Y. S., \& Park, K. D. (2013). Assessing the effects of perceived value and satisfaction on customer loyalty: A 'Green' perspective. Corporate Social Responsibility and Environmental Management, 20.

Julianto, P. A. (2016). Investasi Sektor Medis Tengah Meningkat. Retrieved November $23^{\text {rd }}$, 2019 ,

from:https://money.kompas.com/read/2016/11/03/171946826/investasi.sektor.medis.ten gah.meningkat.

Kaura, V., Durga Prasad, C. S., \& Sharma, S. (2015). Service quality, service convenience, price and fairness, customer loyalty, and the mediating role of customer satisfaction. International Journal of Bank Marketing, 33(4), 404-422.

Keshavarz, Y., \& Jamshidi, D. (2018). Service quality evaluation and the mediating role of perceived value and customer satisfaction in customer loyalty. International Journal of Tourism Cities, 4(2), 220-244.

Kim, K. H., \& Park, D. B. (2016). Relationships among perceived value, satisfaction, and loyalty: Community-based ecotourism in Korea. Journal of Travel \& Tourism Marketing, 34(2), 171-191.

Kotler, P. (1997). Marketing: An introduction (2 ${ }^{\text {nd }}$ ed.). USA: PrenticeMcGraw-Hill Companies.

Kotler, P. (2000). Marketing Management. New Jersey: Prentice-HalI.

Lasadika, M. R. (2018). The Impact of Service Quality Toward Customer Loyalty Through Customer Satisfaction and Trust as A Mediating Variable. Department of Economics, Universitas Islam Indonesia.

Lewis, B. R. (1991). Service quality: An international comparison of bank customers' expectations and perceptions. Journal of Marketing Management, 7(1), 47-62.

MacStravic, S. (1994). Patient loyalty to physicians. Journal of Hospital Marketing, 10(1), 5161.

Meesala, A., \& Paul, J. (2016). Service quality, consumer satisfaction and loyalty in hospitals: Thinking for the future. Journal of Retailing and Consumer Services, 40, 261-269.

Moliner, M. A. (2009). Loyalty, perceived value, and relationship quality in healthcare services. Journal of Service Management, 20(1), 76-97.

Noermijati, \& AS'AD, A. S. (2014). Pengaruh Kualitas pelayanan dan harga terhadap kepuasan dan loyalitas pelanggan (Studi pada pasien rawat inap di rumah Sakit NU Tuban). Jurnal Aplikasi Manajemen, 11(3), 399-406.

Oliver, R. L. (1981). Measurement and evaluation of satisfaction process in retail settings. Journal of Retailing, 57(Fall), 25-48.

Oliver, R. L. (1999). Whence consumer loyalty? Journal of Marketing, 63(4_suppl1), 33-44. 